\title{
Desain kurikulum mikro sustainable development goals di sekolah menengah pertama
}

\author{
Annisa Fitri ${ }^{\left.1^{*}\right)}$, Rudi Susilana ${ }^{1}$ \\ ${ }^{1}$ Universitas Pendidikan Indonesia
}

\begin{tabular}{l} 
Article Info \\
\hline Article history: \\
Received Jun $12^{\text {th }}, 2021$ \\
Revised Jul $12^{\text {th }}, 2021$ \\
Accepted Jul $27^{\text {th }}, 2021$ \\
\hline
\end{tabular}

\section{Keyword:}

Kurikulum mikro

Persepsi guru

Sustainable development

Sekolah menengah pertama

\begin{abstract}
The implementation of values of sustainable development is an important requirement to prepare future generations. Seeing these needs, it is necessary to design a micro curriculum on sustainable development values. Researchers analyzed the perceptions of 241 science teachers in West Java about the urgency of SD (Sustainable Development) indicators into content that students must learn. The topic of waste pollution and renewable energy are the chosen materials to be studied. Teacher's perception of the urgency of the material indicators can be said to be homogeneous. After that, the researcher made a content design for implementing this curriculum. Three validators who are experienced science teachers provide a constructive evaluation of the content and learning evaluation components.Learning evaluation is expected to be varied by including non-test components to achieve SD competence which emphasizes psychomotor and affective aspects. This curriculum content design already has goals that are in accordance with the expected sustainable development competencies, but the material content and evaluation components need further development.
\end{abstract}

(C) 2021 The Authors. Published by IICET.

This is an open access article under the CC BY-NC-SA license

(https://creativecommons.org/licenses/by-nc-sa/4.0)

\section{Corresponding Author:}

Annisa Fitri,

Universitas Pendidikan Indonesia

Email: annisa.fitri@upi.edu

\section{Pendahuluan}

Konsep pembangunan berkelanjutan mengintegrasikan antara aspek sosial, lingkungan, dan ekonomi. Interaksi ketiga aspek tersebut memberikan pengaruh signifikan atas tercapainya tujuan pembangunan berkelanjutan (Ali, Curriculum Development for Sustainability Education, 2017). Hal ini membedakan antara pendidikan untuk pembangunan berkelanjutan (ESD) dengan pendidikan lingkungan. Dinamika interaksi aspek sosial, ekonomi dan lingkungan menjadikan sifat SD (Sustainable Development) lebih cair untuk masuk ke dalam disiplin ilmu (Robert, 2012). Oleh karena itu upaya menginfusi nilai-nilai ESD ke dalam kurikulum penting dilakukan mengingat sifat ESD yang dinamis serta kontekstual dengan kondisi masyarakat di suatu wilayah.

Sebagian besar poin tujuan pembangunan berkelanjutan berkaitan dengan isu lingkungan, energi, dan kesehatan. Isu-isu tersebut dekat dengan konten kurikulum IPA pada jenjang SMP. Urgensi memasukkan nilai-nilai SD ke dalam konten kurikulum IPA dari sisi perspektif guru IPA di jenjang SMP telah diteliti oleh (Ali, Permanasari, Mulyadi, \& Fitri, 2020) dengan kesimpulan bahwa; (1) Para guru menganggap bahwa nilainilai SD harus dimasukkan secara rinci ke dalam konten pembelajaran IPA di SMP, dan (2) Tidak ada 
perbedaan persepsi secara signifikan diantara para guru IPA mengenai topik esensial yang diajukan, meskipun responden memiliki beragam latar belakang.

Menanggapi kebutuhan nilai-nilai SDG's (Sustainable Development Goals), peneliti berupaya membuat desain kurikulum mikro untuk memasukan nilai SDG's ke dalam mata pelajaran IPA di SMP. Tujuan dari penelitian ini antara lain; (a) Menentukan kompetensi SD yang akan dimasukkan ke dalam konten mata pelajaran IPA di SMP, dan (b) Merancang isi kurikulum mikro SD melalui mata pelajaran IPA di SMP.

Fokus materi lingkungan yang dibuatkan rancangan kurikulum mikro pada penelitian ini adalah pencemaran sampah di bumi, dan energi terbarukan. Permasalahan sampah menjadi perhatian setiap negara di dunia. Peningkatan jumlah sampah yang dihasilkan dari aktivitas manusia semakin mengkhawatirkan. Volume sampah yang dihasilkan oleh setiap negara semakin bertambah seiring dengan pertambahan jumlah populasinya. Di Indonesia, sekitar 200.000 ton sampah dihasilkan setiap hari (Paulo, 2020). Penumpukan volume sampah meninggi setiap hari secara signifikan. Tentu saja hal ini menimbulkan keresahan bagi masyarakat terutama masyarakat sekitar tempat pembuangan sampah akhir (TPA). Efek dari pencemaran sampah yang tak terkendali akan memberikan akibat buruk bagi aspek sosial dan ekonomi. Jejaring antara fenomena pencemaran sampah dan hubungannya terhadap aspek sosial ekonomi perlu diperjelas kepada siswa, agar kesadaran menjaga lingkungan bisa semakin tinggi.

Materi energi terbarukan diperlukan sebagai bentuk edukasi terhadap situasi krisis energi yang terjadi di beberapa negara. Saat ini Indonesia mengalami penurunan produksi minyak sekitar 176 barel/ hari berdasarkan data tahun 2017 dan 2018(BPPT, 2018). Hal ini menunjukkan bahwa Indonesia menuju krisis energi minyak, dikarenakan terjadinya defisit namun kebutuhan akan minyak bumi semakin meningkat. Solusi krisis energi bahan bakar fosil adalah pemanfaatan energi terbarukan. Sumber energi terbarukan adalah sumber energi yang dihasilkan dari sumber daya energi yang berkelanjutan jika dikelala dengan baik, antara lain panas bumi, angin, bioenergi, sinar matahari, aiiran dan terjunan air, serta gerakan dan perbedaan suhu lapisan laut (KESDM, 2007).

\section{Metode}

Penelitian ini berfokus pada pengembangan prototipe yaitu desain kurikulum mikro SD (Sustainable Development). Peneliti mengambil data pendahuluan (preliminary) dari penelitian sebelumnya yang dilakukan oleh (Ali, Permanasari, Mulyadi, \& Fitri, 2020), dimana peneliti juga termasuk kedalam timnya. Data pendahuluan ini bersifat kuantitatif mengenai pandangan 241 guru terhadap urgensi nilai SD yang diinfusi melalui pembelajaran IPA khusus materi pencemaran sampah dan energi terbarukan. Dari data pendahuluan ini, peneliti mendapatkan informasi kompetensi SD yang dibutuhkan oleh siswa SMP berdasarkan pandangan para guru IPA SMP di Jawa Barat.

Proses selanjutnya pengembangan prototipe. Prototipe yang dimaksud adalah desain kurikulum mikro yang dapat diadaptasi guru saat memberikan muatan SD pada pembelajaran IPA di kelas. Desain kurikulum mikro ESD diadaptasi sesuai dengan tahap perancangan kurikulum mikro diantaranya; (1) Perumusan kompetensi, (2) Perumusan tujuan, (3) Perencanaan isi kurikulum, (4) perencanaan implementasi kurikulum, dan (5) perencanaan penilaian hasil belajar.

Instrumen data kuantitatif yang dipilih adalah kuesioner. Kuesioner dalam penelitian ini digunakan untuk mengumpulkan data pandangan guru IPA jenjang SMP terhadap topik-topik SD yang memuat kompetensi SD. Instrumen kuesioner merupakan skala pendapat para guru terhadap pentingnya aitem kompetensi SD untuk diaplikasikan. Terdapat empat pilihan jawaban dalam kuesioner yaitu; (1) Sangat Tidak Setuju, (2) Tidak Setuju; (3) Setuju; (4) Sangat Setuju. Penyebaran kuesioner dilakukan melalui fitur daring yaitu google form.

Pernyataan-pernyataan di dalam kuesioner disusun berdasarkan topik-topik yang sesuai dengan SDG's (Sustainable Development Goals), dan dikaitkan dengan materi IPA Kurikulum Nasional 2013 jenjang SMP. Adapun butir-butir pernyataan yang akan dihadirkan dalam kuesioner disebutkan pada Tabel 1. 
Tabel 1. Kuesioner Infusi SDG's Ke Dalam Kurikulum IPA SMP

Terkait Pencegahan dampak sampah atau limbah, kita perlu melakukan:

\begin{tabular}{|c|c|c|c|c|c|}
\hline \multirow{2}{*}{ No. } & \multirow{2}{*}{ Pernyataan } & \multicolumn{4}{|c|}{ Pilihan Jawaban } \\
\hline & & 1 & 2 & 3 & 4 \\
\hline 1. & Membuang sampah ke tempatnya & & & & \\
\hline 2. & Pengolahan limbah yang sulit terurai dengan tanah & & & & \\
\hline 3. & Memanfaatkan sampah rumah tangga & & & & \\
\hline 4. & Menjaga kebersihan sungai & & & & \\
\hline \multicolumn{6}{|c|}{ Terkait Penanganan sampah atau limbah } \\
\hline \multirow{2}{*}{ No. } & \multirow{2}{*}{ Pernyataan } & \multicolumn{4}{|c|}{ Pilihan Jawaban } \\
\hline & & 1 & 2 & 3 & 4 \\
\hline 5. & Penanggulangan pembuangan sampah & & & & \\
\hline 6. & Pemanfaatan sampah sebagai barang berguna & & & & \\
\hline 7. & Pemanfaatkan sampah sebagai bahan bakar alternatif & & & & \\
\hline 8. & $\begin{array}{l}\text { Menghindari pemebakaran sampah yang mengakibatkan } \\
\text { polusi udara }\end{array}$ & & & & \\
\hline
\end{tabular}

Terkait Pencegahan terjadinya krisis energi, kita perlu:

\begin{tabular}{|c|c|c|c|c|c|}
\hline \multirow{2}{*}{ No. } & \multirow{2}{*}{ Pernyataan } & \multicolumn{4}{|c|}{ Pilihan Jawaban } \\
\hline & & 1 & 2 & 3 & 4 \\
\hline 9. & Memahami berbagai dampak dari pemborosan energy & & & & \\
\hline 10. & Menyadari bahaya krisis energi & & & & \\
\hline 11. & Membiasakan perilaku hemat energi listrik & & & & \\
\hline 12. & Menghemat penggunaaan bahan bakar fosil & & & & \\
\hline \multicolumn{6}{|c|}{ Terkait Penanggulangan krisis energi, setiap orang seharusnya: } \\
\hline \multirow{2}{*}{ No. } & \multirow{2}{*}{ Pernyataan } & \multicolumn{4}{|c|}{ Pilihan Jawaban } \\
\hline & & 1 & 2 & 3 & 4 \\
\hline 13. & $\begin{array}{l}\text { Paham bahwa energi itu ada yang terbarukan dan ada yang } \\
\text { tidak dapat terbaharukan }\end{array}$ & & & & \\
\hline 14. & Memahami perlunya penanggulangan krisis energi & & & & \\
\hline 15. & Menggunakan peralatan listrik yang hemat energi & & & & \\
\hline 16. & Berusaha menemukan energi alternatif & & & & \\
\hline
\end{tabular}

Setelah persepsi guru tentang urgensi nilai SDG's dimasukkan ke dalam kurikulum IPA SMP, peneliti membuat desain konten kurikulum mikro SDG's. Konten kurikulum terbagi atas dua bab, yaitu Bab Pencemaran Sampah di Bumi, dan Bab Energi Terbarukan. Adapun desain konten kurikulum mikro yang telah disusun peneliti sebagai berikut;

Tabel 2. Konten Implementasi Kurikulum Mikro: Pencemaran Sampah di Bumi

Bagian Kurikulum Mikro

Tujuan Pembelajaran

Konten Implementasi Kurikulum
Menjelaskan proses membuang sampah dan memisahkannya

Menguraikan proses pengolahan sampah anorganik yang sulit diurai tanah

Melakukan upaya pengolahan sampah rumah tangga menjadi barang dengan nilai tambah

Penjelasan tentang membuang sampah pada tempatnya

Penjelasan jenis-jenis sampah

Penjelasan proses pemisahan sampah

Pengolahan sampah anorganik, termasuk sampah rumah tangga menjadi barang dengan nilai tambah Evaluasi berbentuk teka teki silang

Uji kompetensi mandiri 
Tabel 3. Konten Implementasi Kurikulum Mikro: Energi terbarukan

Bagian Kurikulum Mikro

Tujuan Pembelajaran $\quad$ Menjelaskan dampak sosial ekonomi dari

pemborosan energi

Menjelaskan bahaya krisis energi

Membiasakan hemat energi listrik

Memahami alternatif energi selain energi fosil

Menyajikan desain sederhana energi terbarukan

Konten Implementasi Kurikulum

Penjelasan pengertian krisis energi

Penjelasan jenis-jenis energi terbarukan

Contoh nyata pemanfaatan energi terbarukan di

beberapa negara, seperti Denmark, Belanda, dan

Rusia.

Evaluasi Hasil Belajar

Tabel evaluasi perilaku boros energi

Evaluasi berbentuk teka teki silang

Uji kompetensi mandiri

Pembuatan desain rumah hemat energi (dengan

energi terbarukan)

Sebanyak 3 orang guru IPA SMP berperan menjadi validator konten kurikulum mikro. Pengambilan data validasi konten dilakukan dengan teknik wawancara terstruktur menggunakan tabel kuesioner. Validator pertama merupakan guru IPA dengan pengalaman mengajar lebih dari 4 tahun. Validator kedua dan ketiga merupakan guru IPA senior dengan pengalaman mengajar lebih dari 10 tahun. Ketiga validator memberikan penilaian terhadap konten kurikulum mikro yang berbentuk modul sederhana. Indikator penilaian konten kurikulum meliputi kaitan dengan kondisi sosial masyarakat Indonesia, dinamika lingkungan abad 21, dan keterhubungan dengan konten kurikulum 2013.

\section{Hasil dan Pembahasan}

Materi Sustainable Development yang Perlu Dimasukkan ke Dalam Pembelajaran IPA SMP

Pada data pendahuluan, sebanyak 241 responden guru IPA mengisi kuesioner. Profil responden memiliki keberagaman, mulai dari jenis kelamin, status kepegawaian, latar belakang pendidikan, masa kerja, dan sumber pemahaman SDG's. Berdasarkan kajian terhadap berbagai literatur terkait materi-materi ESD, peneliti mengembangkan kuesioner untuk melakukan Asesmen Merujuk pada hasil kajian literatur itu dirumuskan sejumlah Topik yang dibutuhkan dalam pembelakaran SDG's, dan dari setiap topik itu dikembangkan sejumlah sub-topik yang dijadikan butir-butir kuesioner, yang merupakan elaborasi dari setiap topik itu. Ini dijadikan instrumen untuk melakukan asesmen kebutuhan kompetensi yang merujuk kepada topik-topik yang digali dari berbagai kajian literatur itu.

Hasli uji Validitas Konstruk menggunakan Confirmatory Factor Analysis menunjukkan, bahwa skor setiap topik yang diposisikan sebagai Faktor dari materi SDG's berkorelasi positif signifikan terhadap skor totalnya, dan skor setiap sub-topik yang menjadi elaborasi dari setiap topik juga berkorelasi positif secara signifikan dengan skor total topik atau faktor. Deskripsi hasil asesmen kebutuhan, yang dilakukan untuk mengakses bagaimana para guru Sains di SMP memandang setiap topik itu sebagai kebutuhan untuk dipelajari oleh peserta didik di SMP terkait materi pembelajaran SDG's terkait masing-masing topik dan sub-topiknya adalah sebagai berikut:

\section{Pencegahan Dampak Sampah atau Limbah}

Pada topik ini terdapat 4 sub topik yang ditanyakan kepada responden, yaitu: 1) membuang sampah pada tempatnya, 2) pengolahan limbah yang sulat terurai di tanah, 3) pemanfaatan sampah rumah tangga, dan 4) menjaga kebersihan sungai. Rata-rata skor topik ini adalah 3,465, dan rata-rata setiap sub topik yaitu 3,52; 3,37; 3,48; dan 3,49 dengan variansi 0,38. Dengan melihat rata-rata skor, yaitu dibulatkan menjadi 3 (yang berarti penting), dengan variansi kurang dari 0.5 yang berarti relatif homogen, para guru memandang bahwa topik ini dipandang penting, dan setiap sub-topik dari topik inijuga dianggap penting untuk dimasukkan sebagai materi pembelajaran di SMP.

\section{Penanganan Sampah atau Limbah}

Pada topik ini terdapat 4 sub topik yang ditanyakan kepada responden, yaitu: 1) penanggulangan masalah sampah, 2) pemanfaatan sampah untuk barang berguna, 3) pemanfaatan sampah untuk bahan bakar alternative, dan 4) menghindari pembakaran sampah yang mengakibatkan polusi udara. Rata-rata skor topik 
ini adalah 3,4 dan rata-rata setiap sub topik yaitu 3,$44 ; 3,44 ; 3,31$; dan 3,4 dengan variansi 0,343 . Dengan melihat rata-rata skor, yaitu dibulatkan menjadi 3 (yang berarti penting), dengan variansi kurang dari 0.5 yang berarti relatif homogen, para guru memandang bahwa topik ini dipandang penting, dan setiap sub-topik dari topik ini juga dianggap penting untuk dimasukkan sebagai materi pembelajaran di SMP.

\section{Pencegahan Krisis Energi}

Pada topik ini terdapat 4 sub topik yang ditanyakan kepada responden, yaitu: 1) memahami dampak pemborosan energi, 2 menyadari bahaya krisis energy, 3) membiasakan perilaku hmat listrik, 4) hemat menggunakan bahan bakar dari fosil. Rata-rata skor untuk topik 2 ini adalah 3,41. Rincian rata-rata skor untuk setiap sub topik yaitu 3,$37 ; 3,39 ; 3,51$; dan 3,38, dengan variansi 0,342 . Melihat rata-rata skor, yaitu dibulatkan menjadi 3 (yang berarti penting), dengan variansi kurang dari 0.5 yang berarti relative homogen, para guru memandang bahwa topik ini dipandang penting, dan setiap sub-topik dari topik inijuga dianggap penting untuk dimasukkan sebagai materi pembelajaran di SMP.

\section{Penanggulangan Krisis Energi}

Pada topik ini terdapat $4 \mathrm{sub}$ topik yang ditanyakan kepada responden, yaitu: 1) memahami keberadaan energi terbarukan dan tak-terbarukan, 2) memahami perlunya penanggulangan krisis energi, 3) menggunakan peralatan listrik hemat energy, dan 4) berusaha menemukan energi alternatif. Rata-rata skor untuk topik ini adalah 3,4. Rincian rata-rata skor untuk setiap sub topik yaitu 3,43; 3,41; 3,43; dan 3,36 dengan variansi 0,316. Melihat rata-rata skor, yaitu dibulatkan menjadi 3 (yang berarti penting), dengan variansi kurang dari 0.5 yang berarti relatif homogen, para guru memandang bahwa topik ini dipandang penting, dan setiap sub-topik dari topik inijuga dianggap penting untuk dimasukkan sebagai materi pembelajaran di SMP.

\section{Konten Implementasi Kurikulum Mikro SD}

Indikator evaluasi dari konten kurikulum mikro yang telah dirancang antara lain tujuan pembelajaran, konten materi, dan bentuk evaluasi pembelajaran. Ketiga komponen ini diharapkan saling terkait satu sama lain.

Tabel 4. Validasi Konten Implementasi Kurikulum Mikro: Pencemaran Sampah di Bumi

\begin{tabular}{rlrcrc}
\hline No & \multicolumn{1}{c}{ Pernyataan } & Validator & & $\begin{array}{c}\text { Rata- } \\
\text { rata }\end{array}$ \\
\hline 1 & $\begin{array}{l}\text { Tujuan pembelajaran pada materi Pencemaran Sampah di Bumi } \\
\text { sudah sesuai dengan tujuan pembelajaran IPA SMP }\end{array}$ & 3 & 4 & 4 & 3.667 \\
\hline 2 & $\begin{array}{l}\text { Tujuan pembelajaran pada materi Pencemaran Sampah di Bumi } \\
\text { sesuai dengan kondisi lingkungan dan sosial abad 21 }\end{array}$ & 3 & 4 & 3 & 3.333 \\
\hline 3 & $\begin{array}{l}\text { Tujuan pembelajaran pada materi Pencemaran Sampah di Bumi } \\
\text { sesuai dengan kondisi sosial di Indonesia }\end{array}$ & 4 & 4 & 3 & 3.667 \\
\hline 4 & $\begin{array}{l}\text { Konten materi Pencemaran Sampah di Bumi sudah sesuai dengan } \\
\text { konten materi pelajaran IPA SMP }\end{array}$ & 3 & 4 & 4 & 3.667 \\
\hline 5 & $\begin{array}{l}\text { Konten materi Pencemaran Sampah di Bumi sesuai dengan kondisi } \\
\text { lingkungan dan sosial abad 21 }\end{array}$ & 3 & 4 & 4 & 3.667 \\
\hline 6 & $\begin{array}{l}\text { Konten materi Pencemaran Sampah di Bumi sesuai dengan kondisi } \\
\text { sosial di Indonesia }\end{array}$ & 4 & 4 & 4 & \\
\hline 7 & $\begin{array}{l}\text { Konten materi Pencemaran Sampah di Bumi mampu menjawab } \\
\text { tujuan pembelajaran yang diharapkan }\end{array}$ & 3 & 4 & 3 & 3.333 \\
\hline 8 & $\begin{array}{l}\text { Bentuk evaluasi pembelajaran sesuai dengan tujuan pembelajaran } \\
\text { yang diharapkan }\end{array}$ & 2 & 4 & 3 & 3 \\
\hline 9 & $\begin{array}{l}\text { Butir pertanyaan pada evaluasi pembelajaran sesuai dengan konten } \\
\text { materi yang disajikan }\end{array}$ & 2 & 4 & 4 & 3.333 \\
\hline & $\quad$ & & &
\end{tabular}

Setiap pertanyaan memiliki 4 pilihan jawaban yaitu ; sangat setuju $=4$, setuju $=3$, tidak setuju $=2$, dan sangat tidak setuju $=1$. Rata-rata skor yang diberikan ketiga validator lebih besar sama dengan 3 , yang artinya secara umum ketiga validator menganggap konten kurikulum sudah layak untuk diimplementasikan. Skor tertinggi diraih pernyataan kesesuaian konten materi dengan kondisi lingkungan sosial di Indonesia. Menurut ketiga validator konten materi dirasa cukup kontekstual dengan situasi saat ini. Skor terkecil ditemukan pada pernyataan nomor 8. Evaluasi pembelajaran dinilai kurang sesuai dengan tujuan pembelajaran yang dirumuskan. Menurut validator pertama, tujuan ketiga dari topik ini yaitu "Melakukan upaya pengolahan sampah rumah tangga menjadi barang dengan nilai tambah" tidak bisa dievaluasi dalam bentuk uji kompetensi yang mengasah ranah kognitif saja. Validator 1 memberikan masukan untuk memilih jenis evaluasi portofolio agar bisa mencapa tujuan ranah keterampilan pengolahan sampah. Di samping itu, dengan 
menggunakan evaluasi non tes atau protofolio, interaksi sosial ekonomi yang muncul akan lebih jelas dibandingkan bentuk evaluasi tes saja.

Tabel 5. Validasi Konten Implementasi Kurikulum Mikro: Energi Terbarukan

\begin{tabular}{clcccc}
\hline No & \multicolumn{1}{c}{ Pernyataan } & \multicolumn{2}{c}{$\begin{array}{c}\text { Validator } \\
\text { V2 }\end{array}$} & V3 & $\begin{array}{c}\text { Rata- } \\
\text { rata }\end{array}$ \\
\hline 1 & $\begin{array}{l}\text { Tujuan pembelajaran pada materi Energi Terbarukan sudah sesuai } \\
\text { dengan tujuan pembelajaran IPA SMP }\end{array}$ & 3 & 4 & 4 & 3.667 \\
\hline 2 & $\begin{array}{l}\text { Tujuan pembelajaran pada materi Energi Terbarukan sesuai dengan } \\
\text { kondisi lingkungan dan sosial abad 21 }\end{array}$ & 4 & 4 & 3 & 3.667 \\
\hline 3 & $\begin{array}{l}\text { Tujuan pembelajaran pada materi Energi Terbarukan sesuai dengan } \\
\text { kondisi sosial di Indonesia }\end{array}$ & 4 & 4 & 3 & 3.667 \\
\hline 4 & $\begin{array}{l}\text { Konten materi Energi Terbarukan sudah sesuai dengan konten } \\
\text { materi pelajaran IPA SMP }\end{array}$ & 3 & 4 & 4 & 3.667 \\
\hline 5 & $\begin{array}{l}\text { Konten materi Energi Terbarukan sesuai dengan kondisi lingkungan } \\
\text { dan sosial abad 21 }\end{array}$ & 4 & 4 & 4 & \\
\hline 6 & $\begin{array}{l}\text { Konten materi Energi Terbarukan sesuai dengan kondisi sosial di } \\
\text { Indonesia }\end{array}$ & 4 & 4 & 4 & \\
\hline 7 & $\begin{array}{l}\text { Konten materi Energi Terbarukan mampu menjawab tujuan } \\
\text { pembelajaran yang diharapkan }\end{array}$ & 3 & 4 & 3 & 3.333 \\
\hline 8 & $\begin{array}{l}\text { Bentuk evaluasi pembelajaran sesuai dengan tujuan pembelajaran } \\
\text { yang diharapkan }\end{array}$ & 3 & 4 & 3 & 3.333 \\
\hline 9 & $\begin{array}{l}\text { Butir pertanyaan pada evaluasi pembelajaran sesuai dengan konten } \\
\text { materi yang disajikan }\end{array}$ & 2 & 4 & 4 & 3.333 \\
\hline
\end{tabular}

Rata-rata skor yang diberikan ketiga validator lebih besar dari 3, yang artinya secara umum ketiga validator menganggap konten kurikulum sudah layak untuk diimplementasikan. Skor tertinggi diraih pernyataan kesesuaian konten materi dengan kondisi lingkungan sosial di Indonesia dan kondisi lingkungan sosial abad 21. Menurut ketiga validator konten materi sudah disusun dengan mengangkat fakta sosial lingkungan terkini. Skor terkecil ditemukan pada pernyataan nomor 7, 8, dan 9. Konten materi pemanfaatan energi terbarukan dianggap kurang mendalam untuk membantu mencapai tujuan pembelajaran. Evaluasi pembelajaran dinilai kurang sesuai dengan tujuan pembelajaran yang dirumuskan. Menurut validator pertama, tujuan keempat dari topik ini yaitu "Menyajikan desain sederhana energi terbarukan" belum difasilitasi secara maksimal pada komponen evaluasi pembelajaran yang masih berfokus pada evaluasi berbentuk tes. Hal ini sesuai dengan (Handayani Dewi, Wayan, \& et.al, 2018) yang menyebutkan bahwa evaluasi pembelajaran variatif dengan memasukkan metode non tes seperti portofolio akan mengasah aspek psikomotorik dan afektif siswa.

\section{Simpulan}

Secara umum, para guru menganggap penting untuk memasukkan indikator kompetensi SD ke dalam pembelajaran IPA dalam bentuk kurikulum mikro yang akan diimplementasikan guru di kelas. Perbedaan profil guru tidak mempengaruhi jawaban mereka terhadap rata-rata jawaban keseluruhan secara signifikan, atau datanya dikatakan homogen. Desain kurikulum mikro memiliki tujuan pembelajaran sesuai dengan kompetensi SD yang diharapkan. Komponen konten materi yang dirancang peneliti perlu dikembangkan lebih lanjut untuk memenuhi kebutuhan informasi siswa, atau dapat merangsang rasa ingin tahu siswa agar mencari informasi lebih luas lagi. Evaluasi pembelajaran pada desain konten kurikulum mikro perlu divariasikan dengan bentuk evaluasi non tes untuk mengasah aspek psikomotorik dan afektif siswa. Hal ini dikarenakan nilai SD lebih ditekankan pada aspek afektif dan psikomotorik yang akan diaplikasikan dalam kehidupan sehari-hari.

\section{Acknowledgement}

Penelitian ini didukung oleh beasiswa Jabar Future Leader dan program penelitian lintas bidang UPI (Universitas Pendidikan Indonesia). Terimakasih kepada Prof. Mohammad Ali dari program studi 
Pengembangan Kurikulum UPI, sebagai penasehat yang memberikan masukan dan evaluasi konstruktif terhadap prosses penelitian ini.

\section{Referensi}

Ahlberg, M. (2013). RCE Espoo: NatureGate-Promoting Species Identification for Conservation and Sustainable Use of Biodiversity. Traditional Knowledge and Biodiversity, 84-89.

Aidrina. (2014). Sustainable development, e-learning and Web 3.0. . Journal of Information, Communication and Ethics in Society, 157-176.

Akker, J. V. (2007). An Introduction to Educational Design Research. Netherlands: Netherlands Institute for Curriculum Development.

Ali, M. (2017). Curriculum Development for Sustainability Education. Bandung: UPI Press.

Ali, M. (2019). Research Methods In Sustainablitiy Education. Bandung: UPI Press.

Ali, M., \& Susilana, R. (2021). Perancangan Kurikulum Mikro: Profesionalisme Guru Untuk Pendidikan Berkualitas. Depok: Raja Grafindo Persada.

Ali, M., Permanasari, A., Mulyadi, D., \& Fitri, A. (2020). Teacher's Perception Of ESD Related Themes Potentially Included In Junior High School Science. The 2'nd International Conference on Community Engagement and Education for Sustainability Development.

Altin, A. (2014). Environmental awareness level of secondary school students: A case study in Balıkesir (Türkiye). Procedia - Social and Behavioral Sciences, 1208-1214.

Alvaro, C. E., Abad, A. M., \& Nudelman, N. (2019). Fashion Libraries as a Means for Sustainability Education. An Exploratory Case Study of Adolescents' Consumer Culture. , 100-120.

Becker, C. (2019). Fashion Libraries as a Means for Sustainability Education. An Exploratory Case Study of Adolescents' Consumer Culture.

BPK. (2018, Mei 07). Peraturan Undang-Undang RI. Retrieved Desember 30, 2020, from BPK RI: https://peraturan.bpk.go.id/Home/Details/39067/uu-no-18-tahun-2008

BPPT, R. (2018, September 25). Indonesia Darurat Energi. Retrieved Januari 01, 2020, from Badan Pengkajian dan Pengembangan Teknologi: https://www.bppt.go.id/teknologi-informasi-energi-dan-material/3296-bpptindonesia-darurat-energi

Capelo, A. (2013). Education for Sustainable Development on Secondary School in East Timor. Asian Education and Development Studies, 3, 98-117.

Cebrian, G., David, P., \& Moraleda, A. (2019). Perceptions of Sustainability Competencies amongst Spanish preservice Secondary School Teachers. International Journal of Sustainability in Higher Education, Vol.20 No.7, 1171-1190.

Cruz, R., Harasawa, H., \& Lal, S. W. (2007). Impacts, Adaptation and Vulnerability. Japan: Asia Climate Change .

Fachlevi, T. A. (2015). Dampak dan Evaluasi Kebiijakan Pertambangan Batubara di Kecamatan Mereubo. Risalah Kebijakan Pertanian dan Lingkungan, 170-179.

Furusawa, R., \& Mushakoji, K. (2013). RCE Chubu: Multicultural Dialogue for Sustainability- The Biodiversity Cyber Dialogue Project. Traditional Knowledge and Biodiversity, 78-83.

Gay, L., Mills, G., \& Airasian, P. (2009). Educational Research: Competencies for Analysis and Applications (Ninth ed.). New Jersey: Pearson Education, Inc.

Handayani Dewi, A. P., Wayan, D. I., \& et.al. (2018). Pengaruh Pendekatan Contextual Teaching and Learning Berbasis Penilaian Portofolio Terhadap Kompetensi Pengetahuan IPA. Journal for Lesson and Learning Students, 237-242.

IISD. (2015). Sustainable Development. Retrieved Desember 30, 2020, from International Institute for Sustainable Development: https://www.iisd.org/about-iisd/sustainable-development

Iyer, P., Clark, D., \& Aggleton, P. (2013). Barriers to HIV and Sexuality Education in Asia. Health Education, 118132.

Kemenkes, R. (2018). Info Data Kemenkes RI. Retrieved Desember 30, 2020, from https://www.kemkes.go.id/download.php?file=download/pusdatin/infodatin/InfoDatin-HIV-AIDS-2018.pdf

KESDM, R. (2007, Agustus 10). UU No 30 Tahun 2007. Retrieved Januari Jum'at, 2020, from esdm.go.id: https://jdih.esdm.go.id/peraturan/uu-30-2007.pdf

Neelima, J., Singh, R., Bal, R., Ladhar, S., \& Saxena, S. (2013). RCE Chandigarh: Enhancing Understanding About Wetland Ecosystems among Students. Traditional Knowledge and Biodiversity, 72-77.

Orellana, R. A. (2017). Pro-Environmental Attitudes and Teaching Practice in Secondary Located in Natural Protected Areas From The Perception of Students: The Case of Nijar Fields (Almeria-Spain). Social and Behavioural Sciences, 237, 1112-1118.

Paulo, D. A. (2020, March 22). Indonesia stands at the crossroads of a waste crisis and plastics problem. Retrieved Desember 30, 2020, from CNA Insider: https://www.channelnewsasia.com/news/cnainsider/indonesia-standscrossroads-waste-crisis-plastics-problem- 12564234 
Raniga, U. I., \& Andamon, M. M. (2014). Embedding Sustainability Education in a Built Environment Curriculum. Transforming Higher Education and Creating Sustainable Societies, 56-77.

Robert, K. W. (2012). What is Sustainable Development? Goals, Indicators, Values, and Practices. Environment: Science and Policy for Sustainable Development, 8-21.

Salfarina, A. G. (2013). RCE Penang: Traditional Medicine, Biodiversity, and Health in Rural Communities. Innovation in Local and Global Learning Systems for Sustaianability: Traditional Knowledge and Biodiversity, 58-63.

Savageau, A. E. (2013). Let's Get Personal: Making Sustainability Tangible to Students. International Journal of Sustainability in Higher Education, 15-24.

Setyowati, D. L. (2019). Pendidikan Kebencanaan. Bahan Ajar Universitas Negeri Semarang, 1-50.

Siriwattananon, L., Machito, M., \& Bunthan, N. (2013). RCE Greater Phnom Penh: Promotong ESD Through Food, Agriculture and Environment Education in ELementary School and Rural Communities. Traditional Knowledge and Biodiversity, 54-57.

Sittiyanpaiboon, A., Havanon, S., \& Tabucanon, M. (2013). RCE Cha-am: Biodiversity and Education for Sustainable Development. Traditional Knowledge and Biodiversity, 68-71.

Susilana, R. (2017). Model PPSI-Kemp. Retrieved January 12, 2021, from file.upi.edu: http://file.upi.edu/Direktori/FIP/JUR._KURIKULUM_DAN_TEK._PENDIDIKAN/196610191991021RUDI_SUSILANA/KP10c1-Model_PPSI-Kemp.pdf

Takala, A. (2018). A Decade of Finish Engineering Education For Sustainable Development. International Journal on Sustainability in Higher Edcuation, 20, 170-186.

UN. (2015, Desember). 17 Sustainable Development Goals. Retrieved Desember 30, 2020, from Sustainable Development: https://sdgs.un.org/goals

Wahyudin, D. (2018). Peace Education in The Context of Education for Sustainable Development. Journal of Sustainable Development and Research, 21-32.

WHO. (2018, September 18). A child under 15 dies every 5 seconds around the world. Retrieved Desember 30, 2020, from World Health Organization: https://www.who.int/news/item/18-09-2018-a-child-under-15-diesevery-5-seconds-around-the-world-

WHO. (2018). HIV-AIDS. Retrieved Desember 30, 2020, from Health Topics: https://www.who.int/healthtopics/hiv-aids/

WHO. (2019, June 27). 1 in 3 people globally do not have access to safe drinking water unicef who. Retrieved Desember 30, 2020, from World Health Organization: https://www.who.int/news/item/18-06-2019-1-in-3people-globally-do-not-have-access-to-safe-drinking-water-unicef-who

Wilkinson, C. (2004). Status of Coral Reefs of the World. Townsville: Australian Institute of Marine Science. 